\title{
LA CREACIÓN...O... LA DICHA DE PARTIR A NINGUNA PARTE
}

\author{
VÍCTOR LÓPEZ RACHE
}

Manizales, 2010-02-04 (Rev. 2010-07-26)

El exceso de claridad impuso el discurso de Los Fines e impide el ejercicio sincero del escritor en la creación literaria. La tecnociencia y los medios de comunicación han transmutado el lenguaje y han reducido el principio de realidad en favor de la expansión de fantasías tan extremas que sociedades, con vocación futurista, han retrocedido a estadios primitivos del miedo y la religiosidad. Como si fuera poco ha surgido el AutorClic, cuya virtud consiste en redactar para consumidores de publicaciones que no saben leer, y gracias a la indiferencia de la crítica, se ha apoderado de las emociones y del imaginario. Si el escritor no quiere convertirse en un notario de distorsiones, debe descubrir el misterio para, luego, contribuir a hallar la realidad; sólo entonces, las generaciones del futuro leerán obras, de esta época, en cuyas páginas fluirá el alma y la vida de una comunidad. Para lograrlo, puede encontrar la llave en la experiencia de los grandes escritores del ayer...

***Tener fe en el arte de la creación es desobedecer en silencio y partir con la esperanza de llegar a ninguna parte. Debe ser un viaje desinteresado y no esperar como premios ulteriores el aura que irradia los complejos de Adán y de Cristo. Con un creador nada comienza. Partir de la nada invita a quedarse en la nada, para terminar en la nada. La obra tampoco tiene la obligación de dividir el tiempo en Antes y Después como consecuencia de una vida de sufrimiento, renunciación y entrega a un espejismo estético.

El talento y la inspiración no son constantes, pero si el autor está dispuesto a morir invocando en su obra el misterio de la palabra, convierte la terquedad en una especie de genialidad indefinida. Dormido y despierto persiste en su error, sin importarle si está dentro o fuera. Morir y renacer en cada intento es ir en la dirección correcta, y la sed y el insomnio sirven de estimulantes a la página, siempre, a punto de iniciar.

El feliz sacrificio del creador auténtico anima a sus seguidores a poner las capacidades en la balanza. El punto de equilibrio es indolente y deja la obra en una oscilación perpetua y su autor, pálido, intuye que, en el arte, la certeza mata tanto como la duda. Pero si su imaginación ha tenido movimiento propio se reconocerá único e individual $\mathrm{y}$, sólo entonces, comprenderá que ningún resultado estético depende de los caprichos de una simple balanza, llámese antología nacional, colección de obras maestras de la lengua, o compilación de las joyas inmortales de la aldea.

Crear es sentirse un ser libre, no un cubo de materia al vaivén de los caprichos de mentes autoritarias. Lograr una obra tranquiliza al autor y perfecciona el espíritu de la comunidad.

Pero, ¿un creador puede sobrevivir al margen de las distorsiones de su tiempo y su lugar?

En épocas como esta, sería un prodigio. A finales del siglo XX La Muerte de la Poesía fue anunciada y con ella vino el auge de la claridad. Todo estaba tan 
claro que la historia, las ideologías, la utopía, habían llegado a su fin. El discurso de Los Fines se tornó en el seductor de las mentes futuristas y allí dirigieron la mirada sin advertir los agujeros insondables ocultos en el esplendor de la claridad. Miles de luminarias inundan el mundo cuando intereses poderosos quieren pasar por alto aquello que avergüenza la razón y mancha la esencia de la criatura humana. El conocimiento predominante aseguró haber descubierto el secreto de lo más pequeño y lo más grande del universo. La inspiración nunca había existido y la noción de misterio había sido un equívoco de creadores temerosos de lo desconocido, afirmaron, incluso, poetas inspirados que escribían poemas misteriosos. Como si las posibilidades creativas careciesen de matices, ignoraron que el arte se adelanta o regresa en el tiempo e insistieron, de nuevo, en el fin de las grandes historias y, entonces, la creación promovida pasó a ser subsidiaria de las redes subliminales de la publicidad.

Los propagadores de Los Fines consideraban resueltas las incógnitas humanas y hablaron de nuevos paradigmas; tan nuevos que la mente no tenía preocupaciones distintas a recibir información. Todo era tan diáfano que nadie entendía nada y, conscientes de su capacidad de persuasión, los medios se metieron en las alcobas a repetir que El Fin de Milenio debía celebrarse de la mano divina para evitar que los males pasados se multiplicaran en los tiempos venideros. Se retrocedió a los estadios primitivos de la religiosidad y comunidades enteras se entregaron a venerar a los pontífices del miedo. La falta de pensadores apocalípticos en Latinoamérica impidió promocionar El Fin de la Magia y, tal vez, ello le permitió al Realismo Mágico prolongar su adiós sobre otras manifestaciones literarias de nuestra lengua. Pero quienes se sentían incómodos en tan hermoso ataúd de fantasías, percibieron que los soplos mágicos de la distracción ocultaban trampas inversas a aquellos prodigios que revelan los practicantes de la magia no comercial.

Los viajes espaciales dejaron dudas acerca de la vecindad del cielo, pero los elegidos del más allá miraron noticias y tuvieron certeza de la existencia del Diablo. Infantilizaron el imaginario, el terror exacerbó los instintos de conservación y se impuso como justicia la ignominia del salvaje. Esta iluminación capciosa redujo la pluralidad del pensamiento, pero dejó un beneficio literario. Durante siglos se había dicho que la poesía era pariente de la religión. Los entendidos citaban como actos poéticos la creación del mundo en siete días y Dios hecho a imagen y semejanza del hombre. Pero no eran actos poéticos, eran mentiras incansablemente repetidas. Y si bien la poesía transciende los límites de la verdad, no puede entenderse como un gesto de aproximación a las habilidades innegables de la mentira. Poesía y religión son opuestas. La religión es local y envejece, la poesía perdura y es universal. La religión es dogma, la poesía es sugerencia. Distintos pasajes de La Biblia se semejan infinitamente a manuales de terrorismo y esa misma distancia los separa de la poesía.

Cuando todo ha llegado a su fin y una farsa planificada ilumina lo existente e inexistente, la única opción es crear. Pero si la creación literaria es hija de la imaginación sincera y prefiere moverse en rutas libres de señales arcaicas y barreras impalpables, ¿cómo continuar el viaje para llegar a ninguna parte?

La naturaleza se transforma sin temerle a los rigores del tiempo y el hombre tiene la necesidad latente de inventar. Entonces, los poetas y escritores, ahora, tenían la posibilidad de inventar el misterio para, luego, hallar la realidad. Y hallar la realidad debía ser un imperativo universal. Manos intocables la tienen refundida en superficies programadas en estudios de televisión, estaciones espaciales y laboratorios subterráneos. La inteligencia y la sensibilidad fueron contaminadas de fantasías extremas. 
Las nuevas tecnologías tenían necesidad de ser nombradas y la falta de imaginación de sus inventores los llevó a apropiarse del lenguaje y, sin pudor, le infligieron mutaciones irremediables a las palabras. Los poderes establecidos repitieron el código y lograron invertir los significados. Desde entonces, Paz significa eliminar a un hombre, una comunidad, una etnia. Libertad implica cárceles, torturas y vejámenes de lesa humanidad. Soberanía, invadir a un país pequeño o el país pequeño entregar su dignidad. Prensa Libre equivale a transmitir, impunemente, las suciedades subliminales entretejidas en las mesas estratégicas de las multinacionales de la comunicación. La palabra, ahora, padece la represión de la Academia de la Lengua y el rediseño en las guillotinas de la tecnociencia y la publicidad.

A través de la imagen vaporosa y el lenguaje transmutado han reducido el principio de realidad $y$, para desmentirlo, institucionalizaron como sentencia invulnerable "La realidad supera a la imaginación", figura imposible, pero útil para exaltar los hechos atroces que suceden cuando la arbitrariedad es guía humana y espiritual.

En momentos en que el artificio maneja el imaginario colectivo, es justo mirar el pasado. En el primer milenio las sirenas dejaron de cantar; callaron a lo largo del segundo, y en el tercero reaparecieron repitiendo distracciones enfermizas con ínfulas de universalidad. En la antigüedad los oídos con cera se cuidaban de sus cantos; su posterior silencio planteó, seguramente, desconfianza; pero su reaparición alienada en la era de la globalización causa pánico. Su repetición incesante guarda intereses pavorosos y, en medio de barrotes invisibles o atados a redes virtuales, los navegantes de la iluminación planetaria debemos escucharlas con el suspenso de futuros náufragos. El subconsciente depende, quizá, de alguna deidad artificial, cuyo fin es controlar la criatura humana y vigilar las fronteras de la galaxia. Una creación tan admirable como perversa.

La tecnociencia es de principios autoritarios, pone todo a su servicio y declara caduco a quien le oponga resistencia. La máquina de escribir, en menos de 20 años, pasó a hacer parte del mito. La palabra página no remite a una cuartilla material y de dimensiones proporcionales a las medidas de la criatura humana. Página, hoy, es una apariencia ajena a materia, volumen y peso. Es un espejismo que obedece a un Clic y allí debe escribirse poesía, cuando el poeta debe conservar algo de la inocencia del hombre en su estado natural. Carta, ventana, ratón, de su tradición milenaria, nada le transmiten a un joven de estos días. La prueba esencial de la existencia de la memoria y la imaginación era el libro; pero los usurpadores de los bienes intangibles ya cogieron la palabra libro para expresar todo lo opuesto a un libro. Los paraísos virtuales ocupan el espíritu, y la falta de una realidad objetiva ha llevado a los corazones inocentes a buscar en los mundos ilusorios su amor concreto. El hombre ni siquiera será necesario para el monótono vicio de la reproducción. Un científico, sonriente, afirmó que si la humanidad desaparece en una catástrofe atómica, nada le pasará a la naturaleza. Una década atrás, otro pensador había dicho que el hombre era tan optimista que creía que estaba a punto de desaparecer. Se intensifica el sarcasmo hacia el humanismo y las ideologías mueren de acuerdo a engaños planificados en centros de pensamiento de avanzada o en agencias de publicidad. Es una mutación dinámica y quienes eligieron la literatura como forma de vida sólo tienen a su disposición una palabra manipulada y unos sueños a punto de ser condicionados por programadores de necesidades tan seductoras como inexistentes.

¿Cómo crear con el humanismo herido y la conciencia individual difuminada en alucinaciones electrónicas? 
Como siempre se hizo y siempre se hará. Más en el borde de la soledad que en el centro de la multitud. Más confiado en el milagro del inconsciente que en el gas pragmático que visualizó La Muerte de la Poesía como el acontecimiento del siglo XX. Más en las experiencias de la vida que en las prebendas de instituciones que necesitan enaltecer y falsear. Los creadores que sobrevivieron a Los Fines de la Claridad deben seguir persistiendo en su error. En su error empezaron y en su error concluirán, pues el creador no debe someterse a las exigencias que van surgiendo de necesidades exteriores a la integridad de su ser. Poca creación literaria dejará, por ejemplo, poner el talento al servicio de conmemoraciones históricas, si ello no proviene de una motivación interior. Lejos del ruido alucinante de la moda estética, trabajará con la pasión de la primera vez y disfrutará la compañía de sus autores favoritos. Con ellos dormirá y en sueños establecerá diálogo de igual a igual e, incluso, los cuestionará. Si en ellos encuentra superadas las carencias del entorno, habrá pasado la prueba en que renuncian los aficionados. Son su consuelo insustituible a sabiendas que debe huirles. A medida que crezca su admiración, debe ubicarlos donde su mano no los alcance. Ellos, los maestros, los dignificados, son capaces de acabar con el mejor de los talentos. Es preferible ser un escritor con su mundo personal, suspendido en el signo de interrogación, que un famoso debiendo deudas impagables que el lector cobrará. En su seguro anonimato él descubre el autor insincero e, irónico, señala la procedencia de ese verso tan celebrado; en qué atmosfera tomó vuelo tan admirable cuento; de qué episodio surgió tal novela; de qué tono prestó el maravilloso eco de su voz. El lector a solas recorre la primera etapa de esa ruta quebradiza y malgeniada que el libro debe superar para comenzar a vivir. Figuras de fama absolutista han muerto apenas el lector descubre en sus libros las luces de estrellas ajenas. Después de siglos, autores proscritos han recobrado vida gracias a su propia luz mantenida bajo el brillo de simples parpadeos de neón.

El creador sobreviviente de las distorsiones de la claridad debe defender su independencia. De lo contrario, puede ser usado como objeto político por esos usurpadores del poder que encuentran en los nacionalismos el refugio a sus inclinaciones macabras. También debe cuidarse de las impertinencias económicas. La necesidad, o la abundancia, les impone a los artistas condiciones imposibles de eludir. Las apuestas pragmáticas, la riqueza y la fama han llevado tantos talentos a la desolación estética como la cárcel, la locura y la miseria.

Los obstáculos aparecen durante la escritura y después de ella. Los de talento los agradecen; los elegidos de la vanidad reaccionan enfurecidos. Sin el silencio, la negación, las envidias vengativas y demás métodos de exclusión, el escritor no tendría cómo saber si lo es. Fuera de las arbitrariedades convencionales de la sociedad, el tiempo es el principal. Todo tiempo es breve para un creador y, sin embargo, su trabajo debe ser lento, respetuoso de los abismos invisibles y de las pausas necesarias. El pasado, presente y futuro lucharán por no dejarse someter a las libertades de su obra. El tiempo del autor es el intemporal y, por eso, logra alejarse de las dinámicas de grupos, escuelas o manifiestos, artífices de buenos propósitos que terminan impidiendo el desarrollo de personajes autónomos que le permitirán identificar su obra con el ser esencial de los demás.

Es una opción dura de sostener. Pues los manipuladores de la época creyeron pocas las alteraciones ocasionadas a la realidad y moldearon el AutorClic, cuya característica esencial es desempeñar oficios ajenos a la literatura y seguir a su agente, y su agente se mueve con la agilidad del mouse para terminar, siempre, donde hay mayor rentabilidad. Si se adapta a las habilidades ratonescas, alcanzará la gloria instantánea. En cambio, si un escritor quiere seguir siendo un hombre de letras será eliminado de ferias, editoriales, traducciones y premios. Si 
sus libros son editados, serán pedestal de autores de visiones extremas. Los creadores de ayer no se ajustan al modelo impuesto y, por ello, se cuestiona su existencia. Se duda que Shakespeare sea el autor de su obra. Nerviosos académicos tratan de demostrar que, al menos, los párrafos no vulgares fueron escritos por un aristócrata de pensamiento refinado y virtuoso en el Arte de Comer y de Vestir. Cervantes tampoco se ajusta al modelo actual y, por eso, en los homenajes exaltan los episodios de su obra que invitan a la carcajada e ignoran la vida dolorosa que le diseñó el poder de su época. Intelectuales menos angustiados por las finezas de los creadores de genio, dictan conferencias explicando por qué no han leído a Shakespeare, Cervantes y otros de suerte similar.

El AutorClic no es un novicio sometido a los despropósitos seductores de agentes y editoriales. Sabedor de sus dones capciosos acomoda su personalidad a las exigencias de los poderes públicos y privados, cita frases efectistas de los inmortales, carece de humor y un chiste de tinte transnacional le basta para sorprender a otro escenario cosmopolita donde, al saludar y despedirse, repetirá: "Nada enaltece tanto a un poeta como el fracaso". No tiene ninguna preocupación distinta al éxito, depende de la admiración ajena y sus producciones van dirigidas a consumidores de papel impreso que no saben leer y viven ansiosos de aventuras, parábolas y perversiones. Es tan adorable que puede publicar engaños vacíos de contenido y de forma. Un editor aseguró que estaba en capacidad de volver best seller un cubo de páginas sin una letra. ¿Para qué inventar la llave que revelará nuevos misterios si el arte, también, es de vencedores e inescrupulosos?

Un blindaje hipnotizante protege al AutorClic. No le inquita saber que la publicidad es el horno crematorio de la creación. Extrae sus engaños de la religión, la historia, el arte, el crimen, o de sus aventuras como turista de las letras. Simplemente el olfato ratonesco del agente propone, un equipo recolecta la información, otro redacta y el AutorClic interrumpe sus empleos antiliterarios, revisa de afán en la pantalla, pone su fotografía y la logística de las editoriales se encarga de exhibirlo en las nebulosas de la fantasía comercial. La publicación de finas pastas se venderá como la obra de un creador y si no encaja en género esotérico, documental, sociológico, ni periodístico, se le impondrá la fascinante marca de Novela. Si le acusan de plagio, los comentaristas de la red internacional de los nuevos saberes le admiraran su extraordinario talento para actualizar, actualizar, siempre actualizar. El dinamismo de la época permite todo. La poesía no será editada, siquiera, para obsequiarla por la compra del engaño de finas pastas. "No insista en regalarlos, señor, encarecen el traslado de las bodegas a las librerías", le dijeron a un poeta días antes de la feria del libro en Bogotá. Claro, si a un AutorClic se le ocurriese exaltar en líneas desiguales las atrocidades de un personaje del horror, el producto recibirá la chispa mágica de los medios, obtendrá el aura de inmensa aceptación y no pocos comentaristas hablarían de la resurrección de la poesía. De paso salvaría de la quiebra a muchas editoriales como lo siguen haciendo las publicaciones que, año tras año, provoca la figura de Hitler, deidad de millones de admiradores secretos que se acostumbraron a consumirlo gracias a los detractores que encontraron en su huella macabra motivaciones históricas, estéticas, políticas y de pensamiento.

El ritmo ratonesco no está solo perfeccionando las condiciones para poner en cuidados intensivos la creación literaria. Después de pasearse en laboratorios de última generación una científica americana concluyó que la naturaleza del hombre no está hecha para leer. La carcajada enemiga de la lectura de Hipno resonó desde la época de los dioses griegos y, a la vez, las multinacionales de la comunicación publicitaron el descubrimiento como una verdad maravillosa y la conspiración en contra de la lectura se aproximó a su nivel óptimo. Es tan dura la 
conspiración que a los mismos escritores les impide leer en la vigilia para releer en sueños. Les ha abreviado el tiempo necesario para enterarse de sus pares, de los predecesores y, algunos, no alcanzan a llegar a los clásicos a quienes, no sólo se les debe aprender, sino enriquecer hallándoles nuevas posibilidades de interpretación.

En este ambiente, controlado en todas las direcciones, poetas y escritores deben crear a pulso. Los críticos esperan una obra capaz de brindarles la oportunidad de descubrir personajes que les permita aventurar hipótesis para ayudar a descubrir la realidad refundida en los diferentes planos de la fantasía, paso previo para liberar a los ciudadanos del imperio de la claridad. Tal vez les asista la razón. Pero en siglos anteriores las dos actividades marchaban juntas. Los críticos sentaban posiciones literarias e iluminaban a los escritores en formación. Los críticos no dejaron en el olvido a Kafka, Proust y, después de seis siglos, rescataron de la biblioteca a la Divina Comedia. Los críticos aventuraban con la misma pasión que los creadores $y$, sin temor, establecían conexiones entre situaciones reales e imaginarias. En la obra de escritores y poetas, excluidos de su tiempo, críticos y académicos descubrieron los monstruos ocultos en la normalidad y profetizaron las posiciones autoritarias y las calamidades que hoy tienen al mundo pendiendo de la sonrisa de la tragedia.

Pero el exceso de claridad también afectó a los críticos y han optado por la indiferencia. Si bien la indiferencia es menos nociva que el elogio, sin crítica, escritores y lectores tendrán menos posibilidades de descubrir los misterios de su entorno. La autocrítica es insuficiente para perfeccionar una obra llamada a perdurar.

Ante la alteración de la realidad, la indiferencia crítica y el hambre multinacional del AutorClic, el creador debe hacer de su obra una experiencia espiritual, como lo dejó escrito el ejemplo de los grandes del ayer. Se hace necesario reescribir incansables veces la frase esquiva. Recobrar la paciencia para hacerlo de rodillas. Experimentar la equivocación creativa de ver el sol en plena noche. Un Clic no puede desaparecer el miedo seductor de enfrentarse a aquello que durante generaciones se llamó la angustia ante la página blanca. La criatura que le confía la vida a la poesía lo hace porque ha encontrado en el arte la posibilidad para sugerir, preguntar, descubrir monstruos y encantos que habitan el alma. Si el cultivador de la palabra es sincero, las generaciones del futuro sabrán de un escritor, de esta época, que murió gritando a sus personajes; de un poeta que murió dándose consejos sobre cómo mejorar el verso que le avergonzó. Los lectores volverán a leer páginas en cuyas líneas fluye el espíritu y la sangre de una comunidad lingüística. Volverán a saber, en fin, de autores de esta época que, antes de llegar a ninguna parte, perfeccionaron su obra hasta cuando les permitió la agonía del breve viaje de la vida. Y, entonces, sólo entonces, quedará escrito que La Muerte de la Poesía no pasó de ser el gas de una intoxicación cerebral que sufrió un No-poeta en momentos previos al surgimiento de Los Fines de la Claridad. 